\title{
Source characteristics of volatile organic compounds during high ozone episodes in Hong Kong, Southern China
}

\author{
J. Zhang ${ }^{1,2}$, T. Wang ${ }^{3}$, W. L. Chameides ${ }^{2,}$, C. Cardelino ${ }^{2}$, D. R. Blake ${ }^{4}$, and D. G. Streets ${ }^{5}$ \\ ${ }^{1}$ School of Geography, Beijing Normal University, Beijing, China \\ ${ }^{2}$ School of Earth and Atmospheric Sciences, Georgia Institute of Technology, Atlanta, Georgia, USA \\ *now at: Nicholas School, Duke University, Durham, North Carolina, USA \\ ${ }^{3}$ Department of Civil and Structural Engineering, Hong Kong Polytechnic University, Hong Kong, China \\ ${ }^{4}$ Department of Chemistry, University of California, Irvine, California, USA \\ ${ }^{5}$ Argonne National Laboratory, Argonne, Illinois, USA
}

Received: 5 March 2008 - Published in Atmos. Chem. Phys. Discuss.: 19 May 2008

Revised: 6 August 2008 - Accepted: 6 August 2008 - Published: 28 August 2008

\begin{abstract}
Measurements of Volatile Organic Compounds (VOC) are analyzed to characterize the sources impacting the Hong Kong area. The ratios of different VOC species, m,pxylenes-to-ethylbenzene, $\mathrm{C}_{6} \mathrm{H}_{14}$-to-toluene and p-xylene-tototal xylenes are used for diagnostic analyses. Photochemical age analysis shows that the sources of reactive aromatics, the most important contributor to the photochemical reactivity, do not appear to be preferentially located in downtown Hong Kong. In addition, they do not appear to be dominated by mobile emissions based on the analyses of speciated VOC data from an earlier study, but related to industrial, waterfront, and fuel-storage activities. The ratios, p-xylene-tototal xylenes and $\mathrm{dSO}_{2} / \mathrm{dNO}_{\mathrm{y}}$, suggest that the anomalously high pollutant concentrations in western Hong Kong in the early morning hours of two episode days appear to have come from transport of urban-type emissions. Comparison of observed ambient ratios of selected VOC and their ratios in the speciated VOC emission inventories for Hong Kong and adjacent Pearl River Delta (PRD) Region gives mixed results. The observed ratio $\mathrm{C}_{6} \mathrm{H}_{14}$-to-toluene is consistent with the speciated version of the VOC emission inventory. The ratios of selected alkanes are not. This may be caused by the inaccuracies in the inventory and/or the speciation method.
\end{abstract}

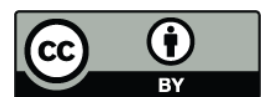

Correspondence to: J. Zhang

(jingzhang@bnu.edu.cn)

\section{Introduction}

Due to the tremendous economic and population growth during the past decades, Hong Kong Special Administrative Region (HKSAR) and the adjoining Pearl River Delta Economic Zone (PRDEZ) of China suffer from air quality problems such as photochemical smog characterized by the unhealthy high concentrations of ozone $\left(\mathrm{O}_{3}\right)$ and fine particles (Kok et al., 1997; Wang et al., 2001; CH2M, 2002; Wang, 2003; Chan and Yao, 2008). Volatile organic compounds (VOC) together with nitrogen oxides $\left(\mathrm{NO}_{\mathrm{x}}\right)$ are important precursors of surface-level ozone. In the Pearl River Delta region, the speciation and sources of VOC have been studied intensively in some field measurements. For example, Guo et al. (2004a, b, 2006, 2007) focused on source apportionment of observations of VOC using statistical analyses. Other previous studies were conducted on the ambient levels of VOC in Hong Kong (Sin et al., 2000; Ho et al., 2002; Lee et al., 2002; Wang et al., 2002, 2005; So and Wang, 2004; Chan et al., 2006; Tang et al., 2007, 2008; Barletta et al., 2008; Liu et al., 2008).

Our previous analysis (Zhang et al., 2007) of the ozone, $\mathrm{NO}_{\mathrm{x}}$ and VOC obtained during an intensive field campaign in the Hong Kong and the Pearl River Delta Pilot Air Monitoring Study from October to December, 2002 showed that on $\mathrm{O}_{3}$ episode days both local emissions and transport from Guangdong Province contributed to the high $\mathrm{O}_{3}$ concentrations. From the simulations using an Observation-Based Model, it was found that the ozone chemistry in Hong Kong during the campaign was limited by VOC, especially the reactive aromatics, of which xylenes and toluene dominated.

Published by Copernicus Publications on behalf of the European Geosciences Union. 
Table 1. Species quantified from analysis of ambient air samples gathered from the different sites in Hong Kong.

\begin{tabular}{lcclcc}
\hline Species & TO & EPD sites & Species & TO & EPD sites \\
\hline Methane & $\mathrm{Y}$ & $\mathrm{Y}$ & Isoprene & $\mathrm{Y}$ & $\mathrm{Y}$ \\
Ethane & $\mathrm{Y}$ & $\mathrm{Y}$ & Ethyne & $\mathrm{Y}$ & $\mathrm{Y}$ \\
Propane & $\mathrm{Y}$ & $\mathrm{Y}$ & Benzene & $\mathrm{Y}$ & $\mathrm{Y}$ \\
n-butane & $\mathrm{Y}$ & $\mathrm{Y}$ & Toluene & $\mathrm{Y}$ & $\mathrm{Y}$ \\
i-butane & $\mathrm{Y}$ & $\mathrm{Y}$ & o-xylene & $\mathrm{Y}$ & $\mathrm{Y}$ \\
n-pentane & $\mathrm{Y}$ & $\mathrm{Y}$ & m-xylene & $\mathrm{Y}$ & $\mathrm{Y}$ \\
i-pentane & $\mathrm{Y}$ & $\mathrm{Y}$ & p-xylene & $\mathrm{Y}$ & $\mathrm{Y}$ \\
n-hexane & $\mathrm{Y}$ & $\mathrm{Y}$ & Ethylbenzene & $\mathrm{Y}$ & $\mathrm{Y}$ \\
2,2-dimethybutane & $\mathrm{Y}$ & & Isopropylbenzene & $\mathrm{Y}$ & $\mathrm{Y}$ \\
2,3-dimethybutane & $\mathrm{Y}$ & $\mathrm{Y}$ & Propylbenzene & $\mathrm{Y}$ & $\mathrm{Y}$ \\
2-methylpentane & $\mathrm{Y}$ & $\mathrm{Y}$ & 3-ethyltoluene & $\mathrm{Y}$ & $\mathrm{Y}$ \\
3-methylpentane & $\mathrm{Y}$ & $\mathrm{Y}$ & 4-ethyltoluene & $\mathrm{Y}$ & $\mathrm{Y}$ \\
n-heptane & $\mathrm{Y}$ & $\mathrm{Y}$ & Methylcyclopentane & $\mathrm{Y}$ & \\
n-octane & $\mathrm{Y}$ & $\mathrm{Y}$ & Cyclohexane & $\mathrm{Y}$ & \\
2,2,4-trimethylpentane & $\mathrm{Y}$ & $\mathrm{Y}$ & 1,3,5-trimethylbenzene & $\mathrm{Y}$ & $\mathrm{Y}$ \\
n-nonane & $\mathrm{Y}$ & & 2-ethyltoluene & $\mathrm{Y}$ & $\mathrm{Y}$ \\
n-decane & $\mathrm{Y}$ & & 1,2,4-trimethylbenzene & $\mathrm{Y}$ & $\mathrm{Y}$ \\
Ethene & $\mathrm{Y}$ & $\mathrm{Y}$ & $\alpha$-pinene & $\mathrm{Y}$ & \\
Propene & $\mathrm{Y}$ & $\mathrm{Y}$ & $\beta$-pinene & $\mathrm{Y}$ & \\
i-butene & $\mathrm{Y}$ & $\mathrm{Y}$ & 1-pentene & & $\mathrm{Y}$ \\
1-butene & $\mathrm{Y}$ & $\mathrm{Y}$ & 2-methylhexane & & $\mathrm{Y}$ \\
cis-2-butene & $\mathrm{Y}$ & $\mathrm{Y}$ & 3-methylhexane & & $\mathrm{Y}$ \\
trans-2-butene & $\mathrm{Y}$ & $\mathrm{Y}$ & 1,2,3-trimethylbenzene & & $\mathrm{Y}$ \\
1,3-butadiene & $\mathrm{Y}$ & $\mathrm{Y}$ & & & \\
\hline & & & & &
\end{tabular}

Note:

a) "EPD sites" represents CW, YL, TC, TM.

b) "Y" means that species of VOCs was measured at that site.

Some anomalous but interesting VOC phenomena were also examined. For example, the 24-h average anthropogenic hydrocarbon concentration observed at Tai O (Plate 1) on 7 November 2002 was higher than or comparable to those measured at upwind sites Central Western/Yuen Long (Plate 1) in this campaign, suggesting that some other significant source of VOC existed other than simply transport from Central Western/Yuen Long. On two episode days, 11 October and 7 November 2002, the VOC concentration and total propyequivalent reactivity in the early morning were much higher than those observed later during the two days and on other episode days. The anomalous behavior on these two days suggested that unusual meteorological patterns caused the pollutant accumulation at Tai $\mathrm{O}$ in the early morning.

In this paper, we will focus on the source characteristics of VOC on the ozone episode days. In order to identify the major sources of different VOC species, especially the reactive aromatics, first we will speciate the VOC emissions from Hong Kong and the Pearl River Delta region based on the emissions by sector of anthropogenic VOC from this region and the speciation profiles for different source types. Then, we will focus on the source characteristics affecting Hong Kong by analyzing the ratios of different VOC species.
Finally, we will assess, in a preliminary fashion, the speciated emission inventory and a speciated emission inventory reported earlier by Streets et al. (2003).

\section{Experimental data}

Our analysis is primarily based on the VOC data collected over the period from October to December 2002 at five locations in Hong Kong: Tai O (TO), Central Western (CW), Yuen Long (YL), Tung Chung (TC), and Tap Mun (TM). TO was operated by the Hong Kong Polytechnic University and the other four were monitoring sites operated by Hong Kong Environmental Protection Department (HKEPD). Also used were data collected during an earlier HKEPD study on the PRD region (CH2M, 2002) at two other sites, Tsing Yi (TY) and Tai Po (TP). TP is located in a waterfront park where emission of industrial processes generated from Tai Po Industrial Estate could be monitored and TY at the entrance portal of a tunnel. A map of Hong Kong showing the locations of each of the sites is presented in Plate 1. The fall season in Hong Kong is characterized by moderate temperatures, light winds out of the northeast and little precipitation. 
Table 2. Emission inventory of VOC by sector for the year 2000 from an earlier PRD study (CH2M, 2002).

\begin{tabular}{lrr}
\hline Sector & HKSAR & PRDEZ \\
\hline Energy & $0.5(1 \%)$ & $7.0(1 \%)$ \\
Industry & $9.5(17 \%)$ & $51.6(9 \%)$ \\
Transportation & $13.6(24 \%)$ & $375.9(66 \%)$ \\
VOC-containing products & $31.4(55 \%)$ & $92.5(16 \%)$ \\
Others & $1.7(3 \%)$ & $47.2(8 \%)$ \\
\hline
\end{tabular}

Note: The emissions are in unit of $\mathrm{Gg}$ (i.e. $10^{9} \mathrm{~g}$ ). The data in parenthesis are in units of percent of total emissions. HKSAR=Hong Kong Special Administrative Region. PRDEZ=Pearl River Delta Economic Zone.

These conditions favor the transport of polluted air from the Asian continent to Hong Kong, as well as the accumulation in Hong Kong of locally emitted pollutants (Wang et al., 2001). Detailed meteorological conditions during the experimental campaign as well as the characteristics of the sites were described by Zhang et al. (2004).

The ambient air samples were collected up to 7 times per day at TO on selected days. At the other four sites operated by HKEPD, the ambient samples were collected once per day every 6 days and lasted for $24 \mathrm{~h}$. A total 73 air samples were collected at TO and 65 at other four sites. The 138 whole air samples were collected with canisters, and then shipped to and analyzed using gas chromatography in the University of California - Irvine (Colman et al., 2001). The VOC detection limit was 5 pptv. And the uncertainty for the VOC was $1 \%-$ $10 \%$ (Colman et al., 2001). Table 1 lists the species that were quantified from the air samples for each of the sites. As can be seen in Table 1, the list of species for TO is somewhat different from that of the EPD sites. However, the species that were measured common to all sites were the most important in terms of ozone photochemistry (accounting for 94-96\% of the total VOC reactivity at each site).

\section{Results and discussion}

\subsection{Speciation of VOC emissions}

Using the emission inventories by sector for the year 2000 from the earlier PRD study (CH2M, 2002) shown in Table 2, which has an uncertainty of below $10 \%$, a detailed analysis of the chemical speciation of VOC emissions from both Hong Kong (HKSAR) and Guangdong Province (PRDEZ) was performed. The VOC emissions were divided into the 47 species measured at TO and other sites operated by HKEPD. The speciation profiles for each source type were drawn from the USEPA SPECIATE 3.2 database (USEPA, 2002, available at: http://www.epa.gov/ttn/chief/software/speciate/ speciate $32 . \mathrm{html}$ ), a repository of total organic compounds as

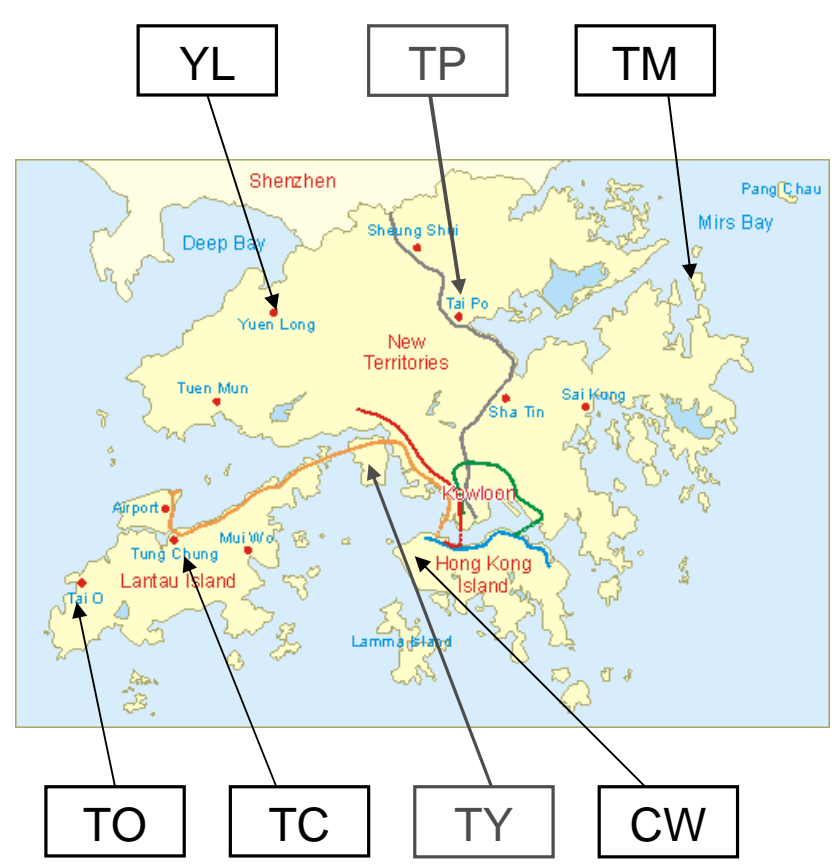

Plate 1 Map of Hong Kong area showing the location of sampling sites (TO=Tai $\mathrm{O}, \mathrm{TC}=$ Tung Chung, $\mathrm{CW}=\mathrm{Central}$ Western, $\mathrm{YL}=$ Yuen Long, $\mathrm{TM}=$ Tap Mun, TY=Tsing Yi, TP=Tai Po).

well as particulate matter speciated profiles for a variety of sources. For this information source, it is assumed that the species profile for a given source type in Hong Kong and PRD is the same as that for the same source type in the West. The speciated VOCs are listed in Table 3.

In general, the speciation of the VOC emissions from the earlier PRD study (CH2M, 2002) is quite different from that of the TRACE-P (Transport and Chemical Evolution over the Pacific) emission inventory (Streets et al., 2003). For example, the emission of isomers of hexane in Hong Kong from the earlier PRD study is about 1/3 of that from the TRACE$\mathrm{P}$ inventory, while the emission of toluene in Hong Kong is $12 \%$ higher (not shown).

\subsection{Source characteristics of VOC: diagnostic analysis}

\subsubsection{Sources of VOC: local emissions vs. transport from} distant sources

Inspection of the distribution and the propy-equivalent reactivity of VOCs (see Chameides et al. (1992) for the description of this method) revealed that anthropogenic hydrocarbons dominate, in which reactive aromatics (which encompasses all aromatics except benzene and is richest in xylenes, toluene, and to a lesser extent trimethylbenzene and ethylbenzene) is the dominant species group (Zhang et al., 2004, 2007). Figure 1 illustrates the propy-equivalent reactivity fractions of xylenes and toluene to the total reactivity of anthropogenic VOC (AHC in figure) and $\mathrm{CO}$ at $\mathrm{TO}$ on ozone 

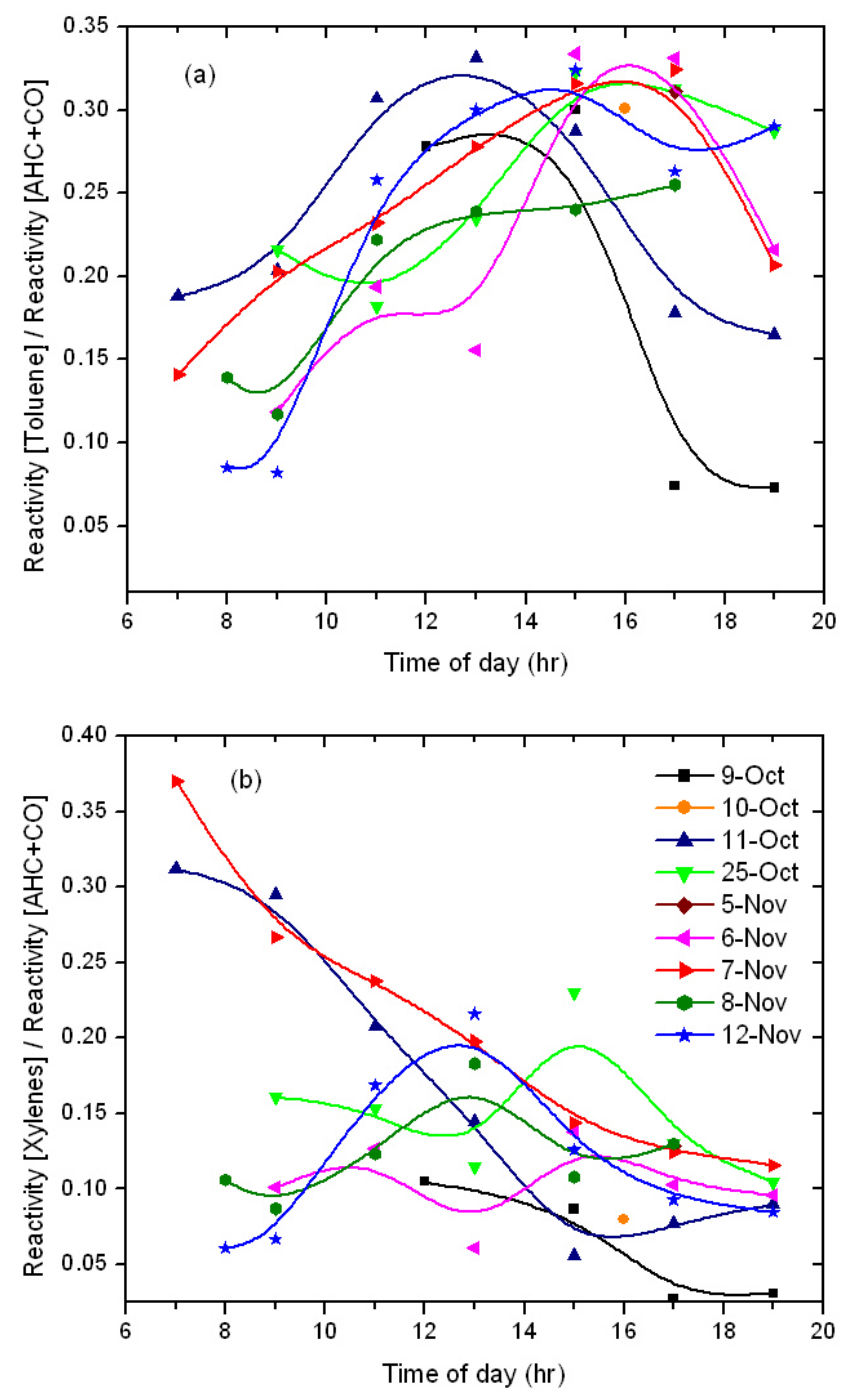

Fig. 1. Fractions of toluene and xylenes to the total propyequivalent reactivity of anthropogenic VOC at TO on all episode days with VOC data.

episode days (defined as a day when the daily peak one-hour averaged $\mathrm{O}_{3}$ concentration was greater than $100 \mathrm{ppbv}$ ). It can be seen that the reactivity fraction of xylenes in early morning of 11 October and 7 November is much higher than that observed during the daytime. This explains in part the high concentrations of anthropogenic hydrocarbons in early morning on these two days in Zhang et al. (2007). However, as the day progressed, the reactivity fraction from xylenes decreased while that of toluene increased. At midday the reactivity fractions of toluene were 4-14\% larger than that of xylenes. On the days other than 11 October and 7 November, on the other hand, the diurnal variations of xylenes and toluene at $\mathrm{TO}$ were more similar, with toluene still tending to increase in importance relative to that of xylenes but less so. This modest increase in the reactivity of toluene relative
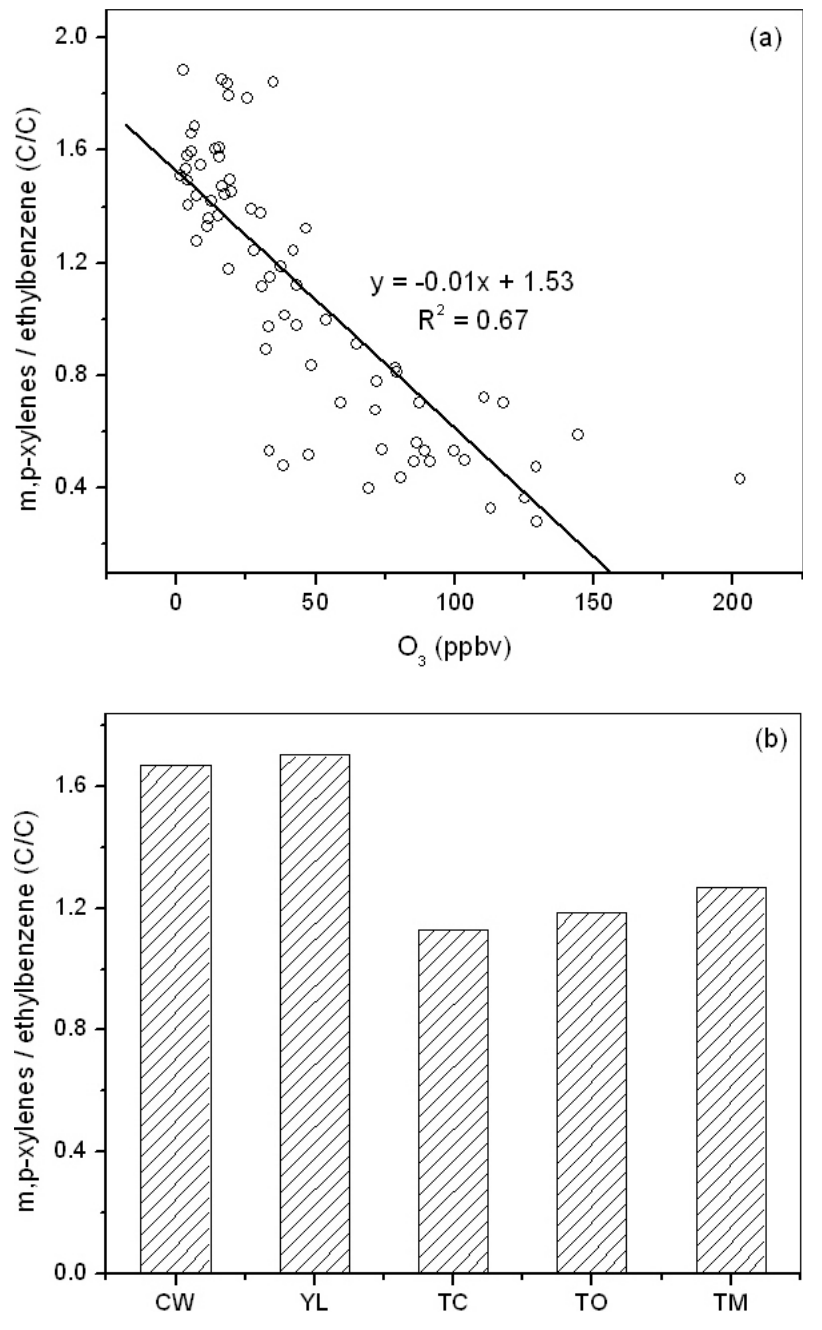

Fig. 2. (a) Scatterplot of simultaneous measurements of $\mathrm{O}_{3}$ and the ratio of $\mathrm{m}, \mathrm{p}$-xylenes to ethylbenzene at TO during the measurement campaign; (b) Ratio of the observed 24-h averaged concentrations of $\mathrm{m}, \mathrm{p}$-xylenes to that of ethylbenzene at all five sites on 7 November 2002 .

to that of xylenes is to be expected, since xylenes are more reactive than toluene. The large increase in 11 October and 7 November is more difficult to rationalize on the basis of photochemistry. This suggests that the source that caused the high concentration of pollutants at TO on 11 October and 7 November was rich in xylenes relative to toluene and that the influence of this source tended to decline with time as these days progressed. Below we will discuss the possible sources of these reactive aromatics.

Due to the meteorological characteristics in Hong Kong area, the monsoon in the fall season favors transport of polluted air from Guangdong Province and accumulation of locally emitted pollutants in Hong Kong (Wang et al., 2001). The air samples we collected may carry information from both local emissions and transport from Guangdong 
Province. Zhang et al. (2007) analyzed the relative roles of local emissions and emissions transported from Guangdong Province in fostering $\mathrm{O}_{3}$ pollution in Hong Kong by carrying out two independent analyses, chemical tracer of $\mathrm{dCO} / \mathrm{dNO}_{\mathrm{y}}$ and isentropic back trajectories. The analyses showed that both local and transported pollutants could act independently or in concert to bring about $\mathrm{O}_{3}$ pollution in the Hong Kong area.

Further insights into the nature of the VOC sources impacting the various sites can be obtained by examining the ratios of VOC species with different photochemical lifetimes (or reactivities) as a measure of the so-called "photochemical age" of the VOC (Nelson and Quigley, 1983). In the analysis presented here, we use the ratio of $\mathrm{m}, \mathrm{p}$-xylenes-toethylbenzene as a metric of photochemical age. We have chosen these two species because their lifetimes are appropriate for distinguishing source contributions between the various sites considered here; that is, the transport time between the various sites on a typical episode day is a few hours while, for a representative afternoon $\mathrm{OH}$ concentration at TO of $5 \times 10^{6} \mathrm{molec} / \mathrm{cm}^{3}$, the xylenes' lifetime is about $3 \mathrm{~h}$ and the ethylbenzene's lifetime is about $8 \mathrm{~h}$. Additionally, both species fall into the same functional group (i.e. reactive aromatics) (Zhang et al., 2004), and thus their ratio will be most relevant to this most dominant group. Another reason to choose this ratio is that various sources of these two species tend to have a similar ratio of about 3.6 (Nelson and Quigley, 1983) as shown in Table 4, so the difference between the ratios observed can be attributed to photochemistry and not emissions. It is worth noting that from the speciated version of emission inventory from CH2M (2002) discussed in Sect. 3.1, this ratio is 4.4 at Hong Kong and 4.0 at Pearl River Delta region, respectively, which is consistent with the value of 3.6 reported by Nelson and Quigley (1983) and $\mathrm{Na}$ et al. (2004). Figure 2a shows the relation between the ratio of m,p-xylenes-to-ethylbenzene and $\mathrm{O}_{3}$ at TO during the measurement campaign. Generally, higher $\mathrm{O}_{3}$ concentrations are indicative of greater photochemical age and so the strong negative correlation between $\mathrm{O}_{3}$ and the m,pxylenes-to-ethylbenzene ratio suggests that the ratio can in fact be used to assess photochemical age.

Figure $2 b$ illustrates the averaged $m$, $p$-xylenes-toethylbenzene ratio observed at each of the five sites on 7 November. CW and YL have relatively high ratios (over 1.6), while TC, TO and TM have lower ratios (about 1.2). These results are generally consistent with what might be expected in the basis of the characteristics of each of the sites. CW is the most urban site and YL is close to a number of industrial facilities and thus we would expect the VOC mixture at these sites to reflect their close proximity to sources. TC, TO and TM, being more rural sites, would be expected to have a more photochemically-aged mix of VOC, reflecting their greater distance from VOC sources. This is consistent with the results from So and Wang (2004) and Guo et al. (2006, 2007). These results and the results from our previous analysis of VOC reactivity in Zhang et al. (2007) also suggest that the additional source of VOC that impacted TC and TO (but not CW and YL) were most likely not local but from source located upwind of the TC and TO but downwind of CW and YL.

\subsubsection{Source of VOC: nature of high levels of VOC sources}

Toluene and xylenes were found to be the most reactive VOC during episode days and their concentrations were relatively enhanced at TC and TO (Zhang et al., 2004), indicating the existence of an additional source of VOC to these sites. The anomalous diurnal variations of toluene and xylenes on 11 October and 7 November further suggest that these two reactive aromatics may have differing sources. Below we examine the observations of speciated VOC to gain insight into the sources of toluene and xylenes.

\section{Ratio of $\mathrm{C}_{6} \mathrm{H}_{14}$-to-toluene}

While ratios of the concentrations of VOC with different photochemical lifetimes can be used to assess the photochemical age of the VOC, the ratios of the concentrations of VOC with similar photochemical lifetimes may be used to identify the relative influence of different source types to the VOC observed at a given site. In the later case, since the VOC have the same lifetime, variations in the ratios of the two species must reflect the influence of different source types that emit the species at differing relative amounts (assuming source output is constant).

To gain insight into the kinds of sources that were responsible for the high concentrations of toluene at $\mathrm{TO}$ and $\mathrm{TC}$, we considered the ratio of $\mathrm{C}_{6} \mathrm{H}_{14}$-to-toluene. (Here we use $\mathrm{C}_{6} \mathrm{H}_{14}$ to represent the isomers of hexane except 2,2-dimethylbutane since its lifetime is about twice that of other isomers.) These species have lifetimes of about 2 days due to reaction with $\mathrm{OH}$ when the 12-h daytime $\mathrm{OH}$ concentration is $1.5 \times 10^{6}$ molecules $\mathrm{cm}^{-3}$. In general, the major source of $\mathrm{C}_{6} \mathrm{H}_{14}$ is mobile; while the major sources of toluene are industrial and fuel storage as well as mobile (see Fig. 3). Thus, one might expect relatively high $\mathrm{C}_{6} \mathrm{H}_{14}$-to-toluene ratios for mobile sources and lower ratios for more industrial sources and sources that reflect evaporative losses and leakages from fuel depots. From the speciated version of emission inventory from $\mathrm{CH} 2 \mathrm{M}$ (2002) discussed in Sect. 3.1, this ratio is about 0.9 for transportation at Hong Kong and Pearl River Delta region, and below 0.1 for industrial and VOC-containing products, which is consistent with some earlier studies (Table 4). This expectation is largely confirmed from examination of Fig. 4a based on data collected at two sites in Hong Kong - Tsing Yi and Tai Po (see Plate 1) during the earlier PRD study discussed in Sect. 2. Tsing Yi is a roadway site located at the entrance to a tunnel and thus is generally dominated by mobile sources. The ratio of $\mathrm{C}_{6} \mathrm{H}_{14}$-to-tolulene is therefore generally high at 
Table 3. Non-methane hydrocarbons measured during the Hong Kong intensive campaign and their apportionment among source categories.

\begin{tabular}{|c|c|c|c|c|c|c|}
\hline \multirow{3}{*}{ Species } & \multicolumn{6}{|c|}{ Percent Apportionment to Source Category } \\
\hline & \multicolumn{3}{|c|}{ HKSAR } & \multicolumn{3}{|c|}{ PRDEZ } \\
\hline & Mobile & Stationary & Natural & Mobile & Stationary & Natural \\
\hline Ethane & 78 & 22 & 0 & 70 & 30 & 0 \\
\hline Propane & 2 & 98 & 0 & 0 & 100 & 0 \\
\hline n-butane & 70 & 30 & 0 & 95 & 5 & 0 \\
\hline i-butane & 16 & 84 & 0 & 60 & 40 & 0 \\
\hline n-pentane & 75 & 25 & 0 & 91 & 9 & 0 \\
\hline i-pentane & 74 & 26 & 0 & 96 & 4 & 0 \\
\hline n-hexane & 50 & 50 & 0 & 80 & 20 & 0 \\
\hline n-heptane & 11 & 89 & 0 & 49 & 51 & 0 \\
\hline n-octane & 100 & 0 & 0 & 100 & 0 & 0 \\
\hline n-nonane & 97 & 3 & 0 & 100 & 0 & 0 \\
\hline n-decane & 98 & 2 & 0 & 99 & 1 & 0 \\
\hline 2,2-dimethylbutane & 91 & 9 & 0 & 100 & 0 & 0 \\
\hline 2,3-dimethylbutane & 68 & 32 & 0 & 94 & 6 & 0 \\
\hline 2-methylpentane & 86 & 14 & 0 & 100 & 0 & 0 \\
\hline 3-methylpentane & 88 & 12 & 0 & 100 & 0 & 0 \\
\hline 2-methylhexane & 0 & 100 & 0 & 0 & 100 & 0 \\
\hline 3-methylhexane & 92 & 8 & 0 & 100 & 0 & 0 \\
\hline 2,2,4-trimethylpentane & 97 & 3 & 0 & 100 & 0 & 0 \\
\hline Methylcyclopentane & 88 & 12 & 0 & 100 & 0 & 0 \\
\hline Cyclohexane & 22 & 78 & 0 & 77 & 23 & 0 \\
\hline Ethene & 100 & 0 & 0 & 96 & 4 & 0 \\
\hline Propene & 99 & 1 & 0 & 90 & 10 & 0 \\
\hline i-butene & 95 & 5 & 0 & 95 & 5 & 0 \\
\hline 1-butene & 64 & 36 & 0 & 78 & 22 & 0 \\
\hline 1-pentene & 77 & 23 & 0 & 100 & 0 & 0 \\
\hline 1,3-butadiene & 100 & 0 & 0 & 23 & 77 & 0 \\
\hline Isoprene & 0 & 0 & 100 & 0 & 0 & 100 \\
\hline Cis-2-butene & 67 & 33 & 0 & 97 & 3 & 0 \\
\hline Trans-2-butene & 43 & 57 & 0 & 95 & 5 & 0 \\
\hline Acetylene & 90 & 10 & 0 & 88 & 12 & 0 \\
\hline Benzene & 78 & 22 & 0 & 91 & 9 & 0 \\
\hline Toluene & 7 & 93 & 0 & 39 & 61 & 0 \\
\hline m-xylene & 12 & 88 & 0 & 33 & 67 & 0 \\
\hline p-xylene & 33 & 67 & 0 & 69 & 31 & 0 \\
\hline o-xylene & 16 & 84 & 0 & 52 & 48 & 0 \\
\hline Ethylbenzene & 32 & 68 & 0 & 72 & 28 & 0 \\
\hline i-propylbenzene & 0 & 100 & 0 & 0 & 100 & 0 \\
\hline n-propylbenzene & 78 & 22 & 0 & 96 & 4 & 0 \\
\hline m-ethyltoluene & 79 & 21 & 0 & 96 & 4 & 0 \\
\hline p-ethyltoluene & 0 & 100 & 0 & 0 & 100 & 0 \\
\hline o-ethyltoluene & 42 & 58 & 0 & 83 & 17 & 0 \\
\hline 1,3,5-trimethylbenzene & 84 & 16 & 0 & 97 & 3 & 0 \\
\hline 1,2,4-trimethylbenzene & 93 & 7 & 0 & 99 & 1 & 0 \\
\hline 1,2,3-trimethylbenzene & 79 & 21 & 0 & 96 & 4 & 0 \\
\hline$\alpha$-pinene & 0 & 0 & 100 & 0 & 0 & 100 \\
\hline$\beta$-pinene & 0 & 0 & 100 & 0 & 0 & 100 \\
\hline
\end{tabular}

Note: HKSAR=Hong Kong Special Administrative Region

PRDEZ=Pearl River Delta Economic Zone 
Table 4. Ratios of VOC in emission sources based on some earlier studies (unit: C/C).

\begin{tabular}{|c|c|c|c|c|c|}
\hline & Sources & $\mathrm{X} / \mathrm{E}^{*}$ & $\mathrm{C}_{6} \mathrm{H}_{14} /$ toluene & $\mathrm{n}-\mathrm{C}_{4} \mathrm{H}_{10} / \mathrm{C}_{2} \mathrm{H}_{6}$ & $\mathrm{C}_{3} \mathrm{H}_{8} / \mathrm{C}_{2} \mathrm{H}_{6}$ \\
\hline \multirow{6}{*}{$\begin{array}{l}\text { Seoul } \\
(\text { South Korea) })^{a}\end{array}$} & Vehicle & $4.31(\mathrm{sp}) 2.43(\mathrm{su}) 4.09(\mathrm{w})$ & $1.00(\mathrm{sp}) 0.69(\mathrm{su}) 0.65(\mathrm{w})$ & $9.87(\mathrm{sp}) 9.66(\mathrm{su}) 3.86(\mathrm{w})$ & $1.57(\mathrm{sp}) 1.99(\mathrm{su}) 1.99(\mathrm{w})$ \\
\hline & Butane fuels & & & $223.38(\mathrm{sp}) 1767.16(\mathrm{su}) 39.24(\mathrm{w})$ & $13.97(\mathrm{sp}) 40.40(\mathrm{su}) 25.95(\mathrm{w})$ \\
\hline & Gasoline & $3.69(\mathrm{sp}) 3.46(\mathrm{su}) 3.40(\mathrm{w})$ & $1.25(\mathrm{sp}) 1.46(\mathrm{su}) 1.21(\mathrm{w})$ & & \\
\hline & Paint solvents & $3.08(\mathrm{sp})$ & $0.004(\mathrm{sp})$ & & \\
\hline & Natural gas & & & 0.04 & 0.32 \\
\hline & $\mathrm{LPG}^{* *}$ & & & 0.10 & 43.47 \\
\hline \multirow[t]{4}{*}{ Sydney $^{b}$} & Exhaust & 3.5 & & & \\
\hline & Petrol & 4.0 & & & \\
\hline & Solvents & 3.5 & & & \\
\hline & Combined & 3.6 & & & \\
\hline Hong Kong ${ }^{c}$ & Combined & & 0.32 & 10.91 & 1.43 \\
\hline Guangdong $^{c}$ & Combined & & 0.44 & 2.64 & 1.51 \\
\hline
\end{tabular}

*: X/E represents m,p-xylenes/ethylbenzene. **: LPG represents liquefied petroleum gas. Data sources: a: Na et al. (2004); b: Nelson and Quigley (1983); c: Streets et al. (2003).

Note: seasons are represented in parenthesis: sp-spring; su-summer; w-winter.

Tsing Yi. The exception is when the VOC concentrations are low (25th percentile), most likely reflecting low-traffic conditions when the site was being impacted by more distant non-mobile sources. The ratio is also low at 50th percentile in observed VOC concentrations because $\mathrm{C}_{6} \mathrm{H}_{14}$ level was close to detection limit $(0.2 \mathrm{ppbv}, \mathrm{CH} 2 \mathrm{M}, 2002)$ at both 25 th and 50th percentile while toluene level was well above the detection limit ( $0.2 \mathrm{ppbv}, \mathrm{CH} 2 \mathrm{M}, 2002)$. Tai Po is situated in an industrial waterfront park, and here the $\mathrm{C}_{6} \mathrm{H}_{14}$-to-toluene ratio was generally low reflecting local industrial processes and/or emissions from ships and other waterborne transport systems as well as fugitive emissions arising from the transport of chemicals and fuels by such waterborne systems, except that when the VOC concentrations are low when the site was being affected by more distant non-industrial sources.

Figure 5a illustrates the $\mathrm{C}_{6} \mathrm{H}_{14}$-to-toluene ratio observed at each of the sites on episode and non-episode days, and Fig. 5b illustrates the diurnal variation in the ratio observed at TO on episode days. Inspection of Fig. 5a reveals that the ratio is depressed at TC and TO compared to other sites on episode days (about 0.23 ). This suggests that the excess abundance of toluene (and perhaps the additional source of VOC in general) at TC and TO is related to industrial, waterfront, and/or fuel-storage emissions as opposed to mobile emissions. Inspection of Fig. 5b indicates that at TO the ratio tends to decrease in the early afternoon at the same time that $\mathrm{O}_{3}$ tends to increase on episode days (Zhang et al., 2007). This result is consistent with the growing contribution of toluene to the total reactivity at TO in the afternoons discussed earlier and suggests that the air masses contributing to the rise of $\mathrm{O}_{3}$ at $\mathrm{TO}$ are more heavily influenced by emissions from industrial, waterfront, and/or fuel-storage than from mobile emissions.
The analyses discussed above and in the previous sections suggest that the additional toluene impacting $\mathrm{TO}$ and $\mathrm{TC}$ are not local and that they arise from industrial, waterfront, and/or fuel-storage activities. A related question is whether these sources are located in Hong Kong or in Guangdong Province. To address this question we first examined the $\mathrm{C}_{6} \mathrm{H}_{14}$-to-tolulene ratios observed at a number of sites throughout Guangdong Province during the aforementioned Hong Kong EPD study (Fig. 4b). We can see that low ratios of $\mathrm{C}_{6} \mathrm{H}_{14}$-to-toluene similar to that observed at Tai Po (i.e., less than 0.2) were observed at a number of sites in Guangdong Province. Such low ratios of $\mathrm{C}_{6} \mathrm{H}_{14}$-to-toluene were also observed in some other studies (Tang et al., 2007, 2008; Barletta et al., 2008; Liu, et al., 2008). This suggests that Guangdong Province cannot be ruled out as a source of the additional toluene observed at TC and TO.

Further insight can be gained by examining a scatterplot between $\mathrm{dCO} / \mathrm{dNO}_{\mathrm{y}}$ (a tracer for distinguishing between pollution from Hong Kong and Guangdong based on their difference in emissions, see Wang et al., 2001; Zhang et al., 2007 and papers cited therein for discussion) and the $\mathrm{C}_{6} \mathrm{H}_{14}$-totoluene ratio observed at TO. The scatterplot is illustrated in Fig. 6. We find a significant negative correlation between the $\mathrm{C}_{6} \mathrm{H}_{14}$-to-toluene ratio and $\mathrm{dCO} / \mathrm{dNO}_{\mathrm{y}}$. The plot suggests that over $30 \%$ of the variability in the $\mathrm{C}_{6} \mathrm{H}_{14}$-to-toluene ratio observed at TO was correlated with a factor associated with pollution from Guangdong Province. This, in turn, implies that emissions from Guangdong Province are responsible, in part, for the high concentrations of toluene observed at TO. On the other hand, it should be noted that the regressions in Fig. 6 were obtained by omitting two outlying data points that were obtained on 9 October that happened to have very high $\mathrm{CO}$ and very low toluene concentrations and were outside the upper $95 \%$ confidence interval of $\mathrm{dCO} / \mathrm{dNO}_{\mathrm{y}}$. If these two points are included in the scatterplot (not shown), the statistical relationship between $\mathrm{dCO} / \mathrm{dNO}_{\mathrm{y}}$ and the $\mathrm{C}_{6} \mathrm{H}_{14}$-to-toluene ratio at $\mathrm{TO}$ is lost. 


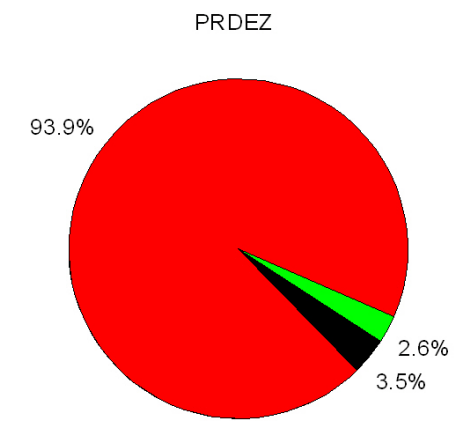

Isomers of hexane
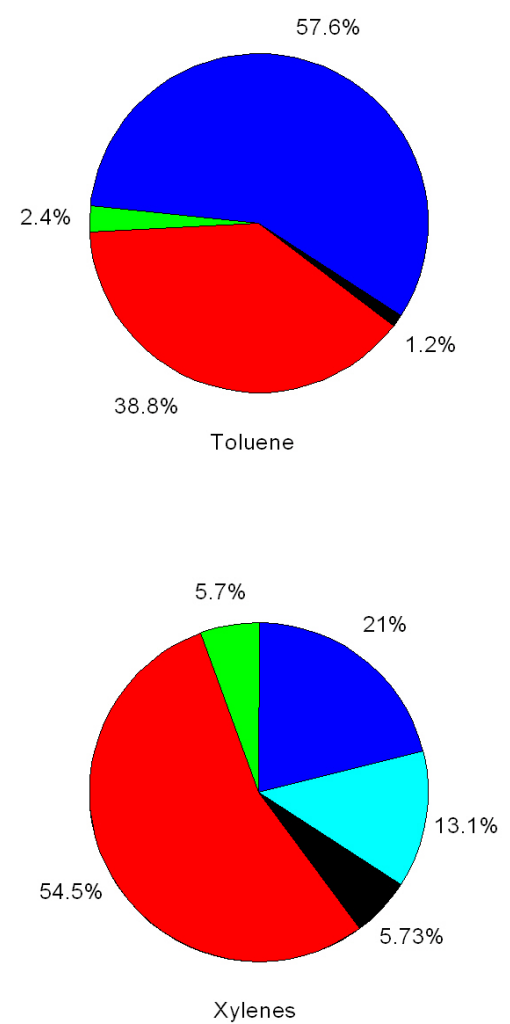

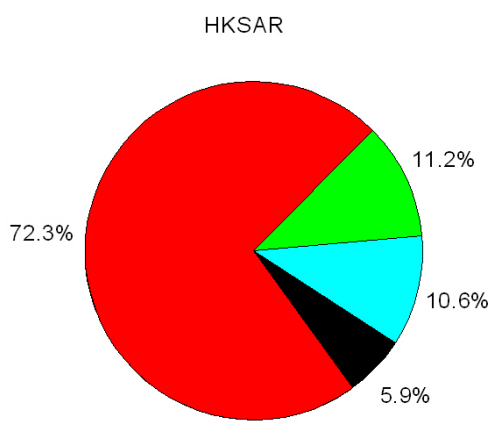

Isomers of hexane
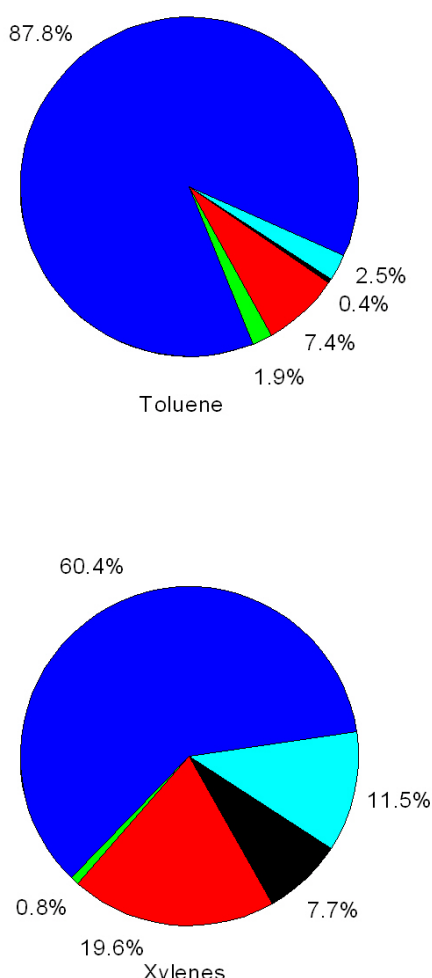

Xylenes

$\square$ Energy $\square$ Transportation $\square$ Industry $\square$ VOC-cont products $\square$ Others

Fig. 3. Emissions of $\mathrm{C}_{6} \mathrm{H}_{14}$, toluene and xylenes by sector for Hong Kong and PRD Region in Guangdong Province of China. Source: Earlier PRD Study (CH2M, 2002).

\section{Xylene ratios}

Recall from our earlier discussion that the observed variations of xylenes in Hong Kong had some similarities to toluene and also some differences. The time-resolved data for TO indicated that on most episode days the reactivity contribution from toluene tended to increase somewhat as the days progressed, a tendency consistent with the fact that xylenes are more reactive than toluene. However, more anomalous behavior was observed at TO on 11 October and 7 November when xylenes dominated the reactivity in the early morning but declined rapidly relative to that of toluene during the late morning and early afternoon. The rapid decline in xylenes' contribution on these two days could be indicative of xylenes and toluene having different sources. In fact, emission inventories for these two species 

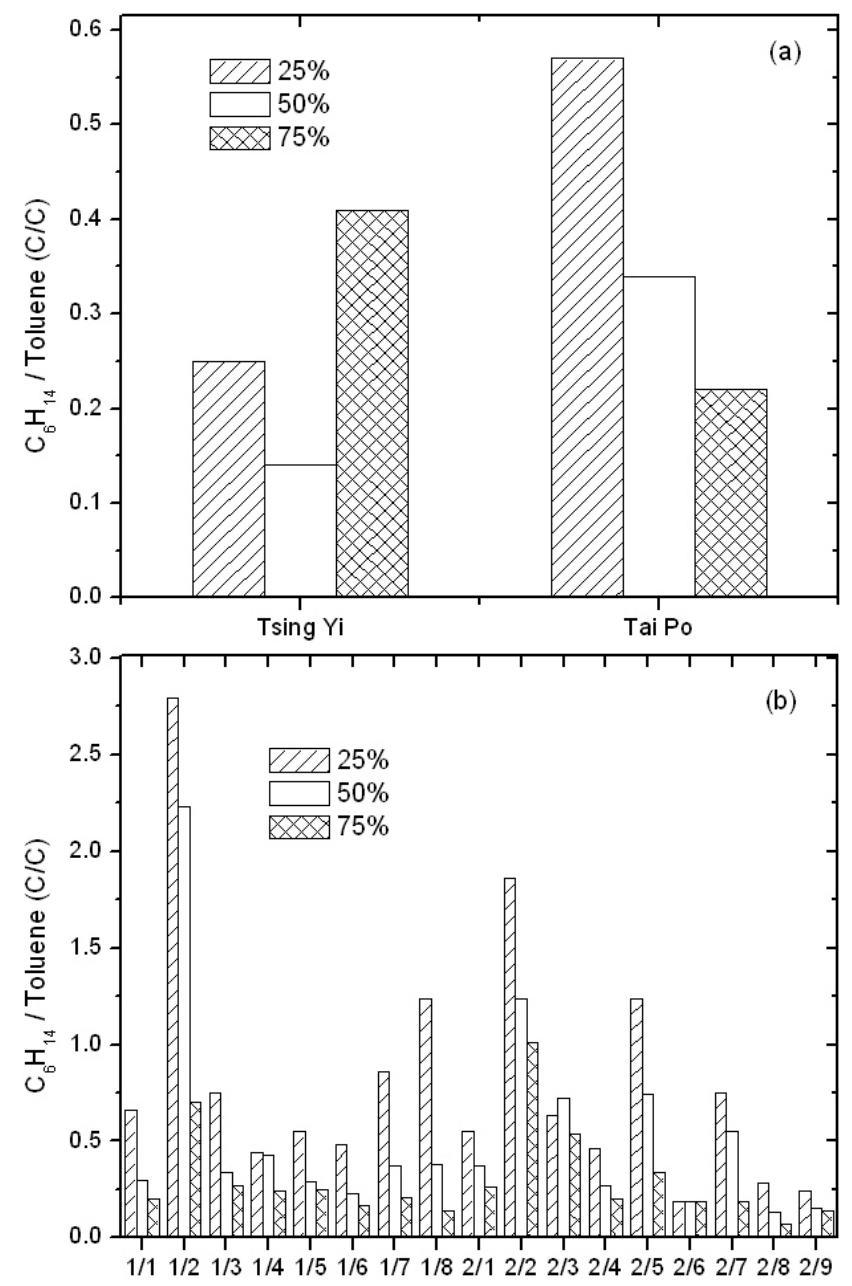

Fig. 4. Ratios of $\mathrm{C}_{6} \mathrm{H}_{14}$-to-toluene at different sites in Hong Kong and PRD region in Guangdong Province for the 25th, 50th, and 75th percentile in observed VOC concentrations from an earlier PRD study (CH2M, 2002). (a) At Tsing Yi and Tai Po; (b) The names of the sites are: 1/1, Dongguan City Changping Town; 1/2, Guangzhou City Conghua City; 1/3, Guangzhou City Guang-Shen Highway; 1/4, Guangzhou City Tianhe District; 1/5, Guangzhou City Huangpu District; 1/6, Jiangmen City Fengjiang District; 1/7, Shenzhen City Nanshan District; 1/8, Zhuhai/Zhongshan City Guangzhu Highway; 2/1, Guangzhou City Baiyunshan; 2/2 Guangzhou City Conghua City; 2/3, Guangzhou City Yuexiu District; 2/4, Guangzhou City Huadu City; 2/5, Guangzhou City Baiyun District; 2/6, Guangzhou City Lianhuashan; 2/7, Guangzhou City Tianhe District; 2/8, Guangzhou City Xinken County; 2/9, Shenzhen City Baoan District.

generally indicate that they do indeed have different sources. Inspection of Fig. 3 derived from the emissions inventory obtained from the earlier PRD study reveals that emissions from the transportation sector tend to be more important for xylenes than for toluene.
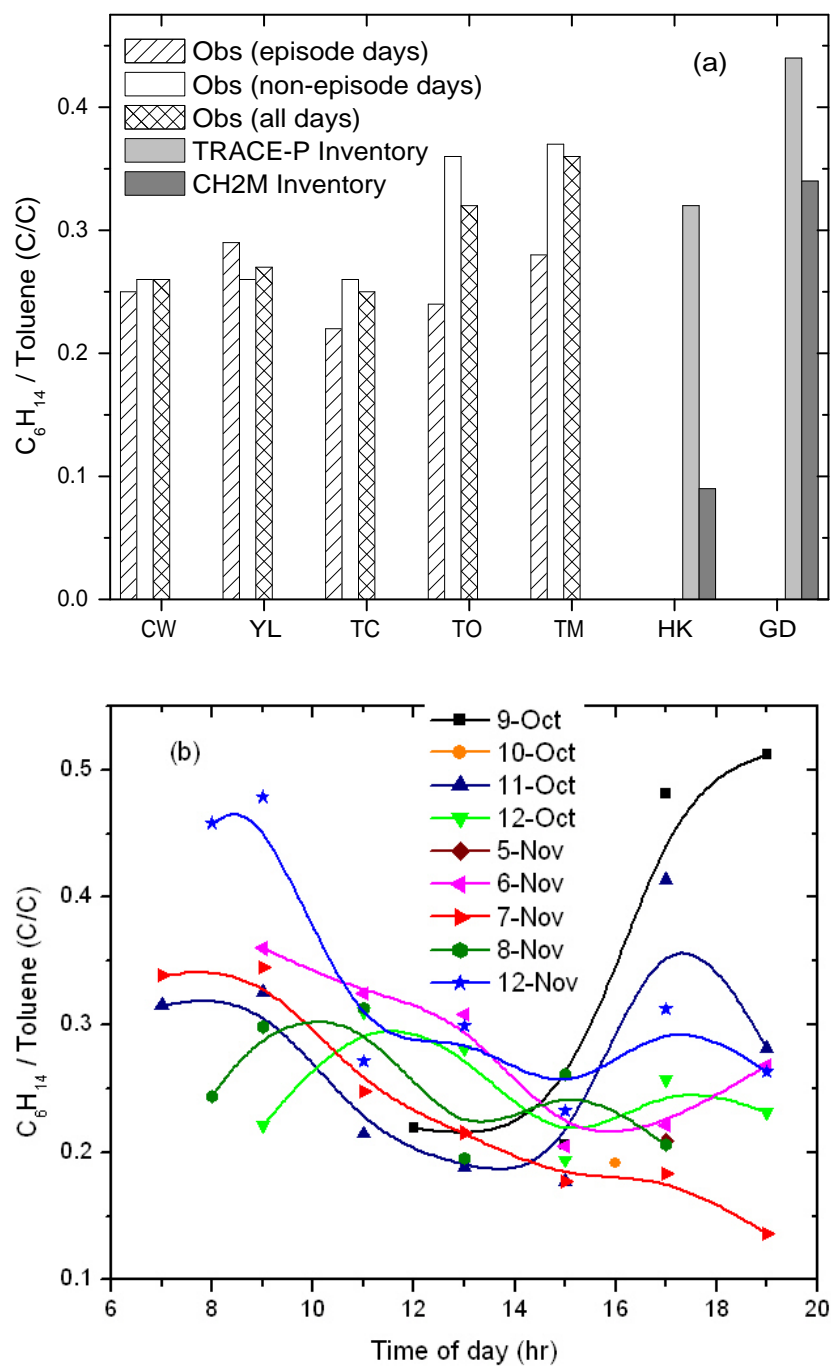

Fig. 5. (a) Average ratio of $\mathrm{C}_{6} \mathrm{H}_{14}$-to-toluene observed in ambient air at different sites in Hong Kong and in the emission inventories for Hong Kong (HK) and Guangdong Province (GD) from the TRACE-P Experiment (Streets et al., 2003) and the earlier PRD study (CH2M, 2002); (b) Observed ratios of $\mathrm{C}_{6} \mathrm{H}_{14}$-to-toluene at $\mathrm{TO}$ as a function of time of day on episode days.

To investigate this possibility we analyzed the ratio of p-xylene to total xylenes as a function of the total xylene concentration (Fig. 7). For most of the data gathered at the EPD sites, the ratio of p-xylene-to-total xylenes hovers around $0.2-0.3$. Thermodynamic equilibrium in the reforming process used in gasoline and aromatics production tends to produce a ratio of p-xylene-to-total xylenes of $\sim 0.25$ (Schauer, J., private communication, 2004). Thus, much of the xylene observed at the EPD sites can be rationalized in terms of emissions related to transportation; e.g., evaporation of gasoline. In the case of TO, however, most of the data points have $\mathrm{p}$-xylene-to-total xylene ratios greater than 0.3 . This suggests that, during most of the episode days, a 


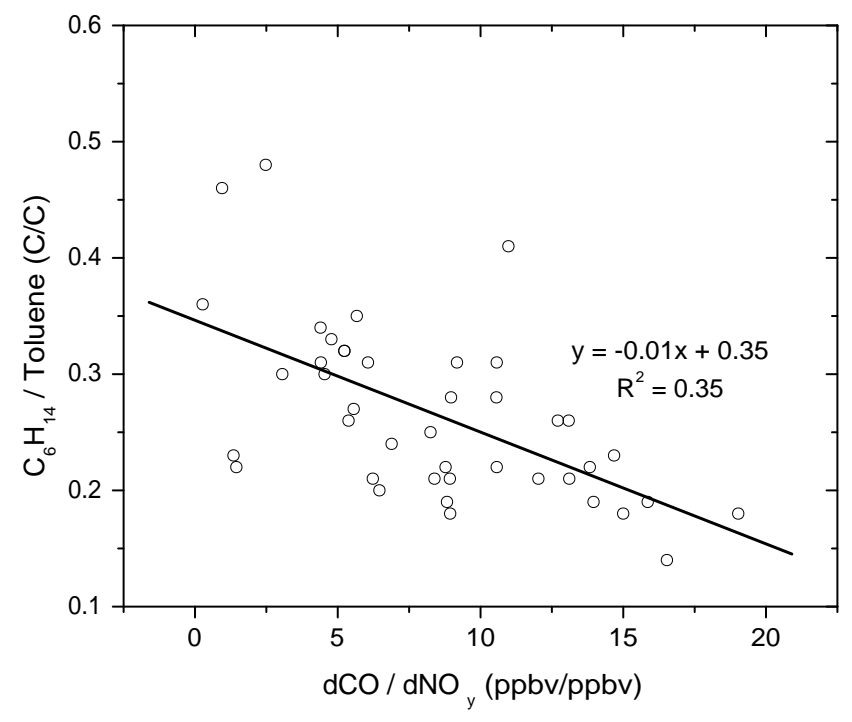

Fig. 6. Scatterplot of the $\mathrm{C}_{6} \mathrm{H}_{14}$-to-toluene ratio versus $\mathrm{dCO} / \mathrm{dNO}_{\mathrm{y}}$ observed at TO.

major source of the xylenes at TO, like that of toluene, was non-mobile and related to industrial/petrochemical activities. This in turn implies that the "additional source" of VOC we inferred earlier for TO and TC that was enriched in reactive aromatics is also likely related to industrial/petrochemical activities.

However, there is a notable exception to the above conclusion. Note in Fig. 7 that there are five data points with extremely high total xylene concentrations (i.e., greater than $50 \mathrm{ppbC}$ ) and the p-xylene-to-total xylenes ratio for these were all around 0.3 , a ratio consistent with a source related to transportation and close to that observed at the EPD sites. Interestingly, all the five data points were observed in the early morning hours of two ozone episode days with anomalously high early morning concentrations of VOC at TO. This suggests that the anomalously high concentrations of pollutants at TO on 11 October and 7 November were most likely associated with transport of urban-type emissions typical of the other EPD sites and not due to emissions from a transient source near TO. This is also corroborated when the "seasonal" ratio of $\mathrm{dSO}_{2} / \mathrm{dNO}_{\mathrm{y}}$ (see Zhang et al., 2007 for the calculation method. The background $\mathrm{SO}_{2}$ and $\mathrm{NO}_{\mathrm{y}}$ concentrations of $1.04 \mathrm{ppbv}$ and $3.37 \mathrm{ppbv}$ were adopted) was examined. Figure 8 shows the ratios observed at TO on 11 October and 7 November 2002 (The "24 hourly" ratios of $\mathrm{dSO}_{2} / \mathrm{dNO}_{\mathrm{y}}$ have the same results). It can be seen that $\mathrm{dSO}_{2} / \mathrm{dNO}_{\mathrm{y}}$ was low (less than 0.1) in the early morning hours, and increased to over 0.2 after $10 \mathrm{a} . \mathrm{m}$. with the highest ratios exceeding 0.45 during the daytime on each of the two days. This suggests that TO was mainly impacted by emissions of transportation type in the early morning on these two days, while the influences from power plant/industry emissions increased during the daytime.

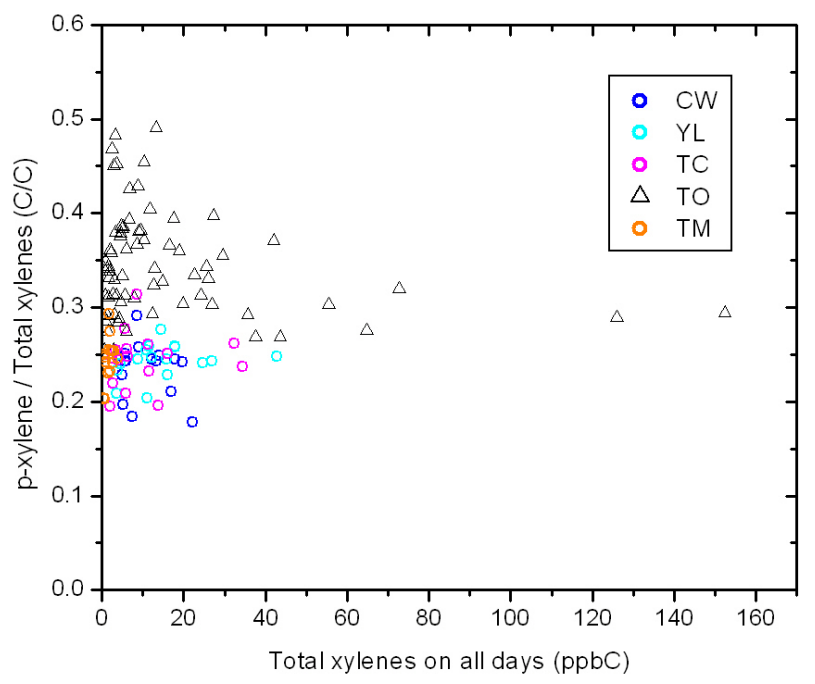

Fig. 7. Observed ratios of p-xylene-to-total xylenes as a function of total xylenes concentration at various sites during the measurement campaign.

\section{Summary}

Analyses of the speciated VOC data suggest that the xylenes observed at the EPD sites on 7 November were dominated by sources related to the transportation sector. However, the additional sources of VOC impacting TO and TC were likely related to petrochemical/industrial, waterfront, and/or fuel-storage activities. Anomalously high pollutant concentrations at TO in the early morning hours of two episode days, on the other hand, appear to have come from transport of emissions from sources similar to those impacting the EPD sites. Negative correlations between $\mathrm{VOC}$ ratios and $\mathrm{dCO} / \mathrm{dNO}_{\mathrm{y}}$ suggest that sources from the Guangdong Province are a significant, but not sole, contributor to the additional VOC observed at TO and TC. By extension it appears likely that Guangdong Province is contributing significantly to the high concentrations of reactive aromatics observed throughout Hong Kong.

\subsection{A preliminary assessment of the emission inventories' accuracy}

To assess the accuracy of existing emission inventories using chemical measurements, several methods have been used. Inverse modeling is one that estimates emissions by comparing observations and model simulations (Hartley and Prinn, 1993; Mulhollan and Seinfeld, 1995; Chang et al., 1996, 1997; Tan et al., 2004). Although it is a potentially powerful tool to resolve the magnitude and spatial allocation of emissions and of values in both scientific understanding and policy making, inverse modeling method is limited by the uncertainties of models. Apart from the inverse modeling, various statistical methods have been used to test inventories for 


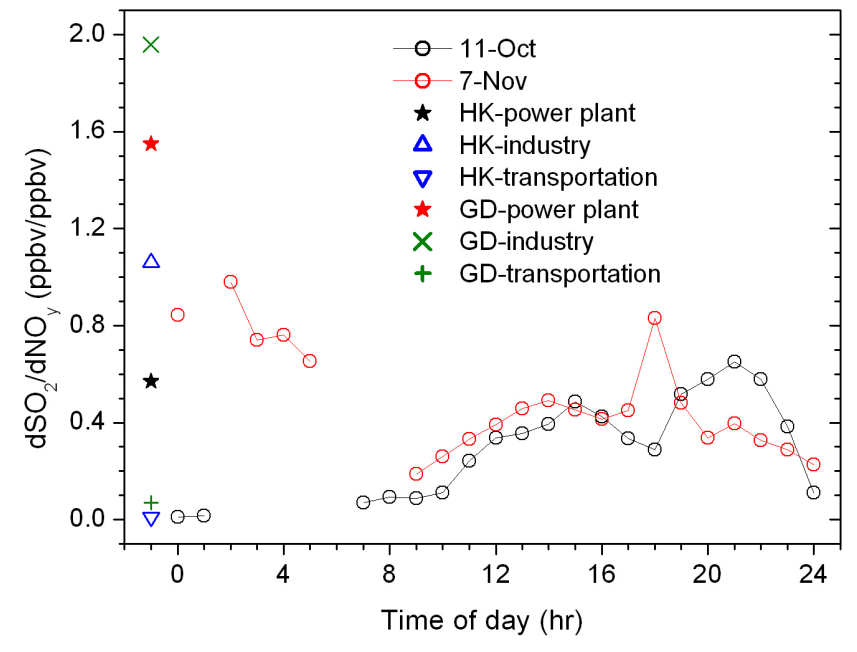

Fig. 8. Diurnal variations of "seasonal" ratio $\mathrm{dSO}_{2} / \mathrm{dNO}_{\mathrm{y}}$ at $\mathrm{TO}$ on 11 October and 7 November, 2002. See Zhang et al. (2007) for the method how "seasonal" ratio $\mathrm{dSO}_{2} / \mathrm{dNO}_{\mathrm{y}}$ is derived. The background $\mathrm{SO}_{2}$ concentration of $1.04 \mathrm{ppbv}$ was adopted (data from Wang et al., 2001).

gaseous and particulate pollutants (Cass and McRae, 1983; Schauer et al., 1996; Schauer and Cass, 2000; Zheng et al., 2002). This approach can be used to determine the contributions of different sources. But it also has limitations: the composition of source emissions needs to be constant with time; all sources that contribute to ambient concentrations at the receptor are identified; and the sources are sufficiently different in terms of their chemical signatures to be easily distinguished at the receptor. Another method of emission testing is based on the comparison of the species ratios from atmospheric measurements and emission inventory (Parrish et al., 1991). This last method will be applied and discussed in this work.

In this section we present the results of a preliminary analyses using the speciated VOC measurements made during the field campaign to assess the accuracy of two existing VOC emission inventories for Hong Kong and the PRD area: (1) A speciated VOC emission inventory prepared by Streets et al. (2003) for the TRACE-P and ACE-ASIA field experiments; and (2) the VOC emission inventory produced as part of the aforementioned earlier PRD study (CH2M, 2002).

\subsection{1 $\mathrm{C}_{6} \mathrm{H}_{14}$-to-Toluene}

One useful approach to checking the speciation of VOC inventories is to compare ambient and emission ratios for VOC species that have similar lifetimes. As noted in Sect. 3.2.2, since VOC species with similar lifetimes react at the same rate, variations in their ratios should only reflect variations in their relative source strengths, and, on average, the ratio of their ambient concentrations should reflect the ratio of their emissions. Here, as in Sect. 3.2.2, we use the ratio $\mathrm{C}_{6} \mathrm{H}_{14}$ -

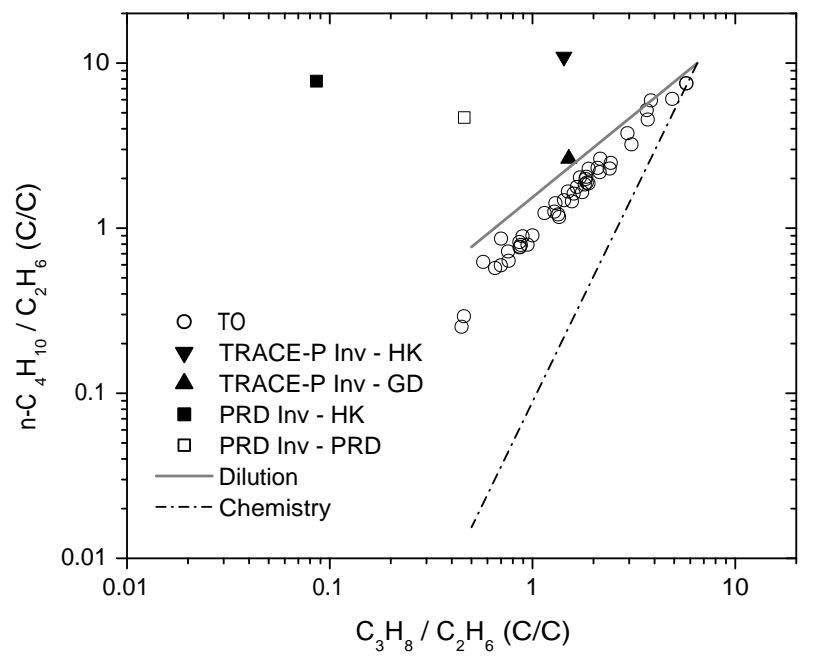

Fig. 9. Ratios of n-butane-to-ethane vs. propane-to-ethane from observations of ambient air at TO and in the emission inventories for Hong Kong (HK) and Guangdong Province (GD) from the TRACE-P Experiment (Streets et al., 2003) and the earlier PRD study (CH2M, 2002). The two lines represent how these ratios would evolve in time as result of dilution only and photochemistry only.

to-toluene to assess the accuracy of the VOC inventories. Figure 5a shows the observed ambient $\mathrm{C}_{6} \mathrm{H}_{14}$-to-toluene ratio at different sites in Hong Kong and the ratio from the two emission inventories for Hong Kong and for Guangdong Province. Inspection of the figure indicates that the ratios from the TRACE-P inventory for Guangdong Province are more than $16 \%$ larger than that obtained from the ambient observations, while those for Hong Kong are comparative to that observed at TO and TM and larger than other sites. This indicates an inconsistency in the inventory. In the case of the inventory from the earlier PRD study, on the other hand, we find that the ambient-measured ratios generally lie between the ratios derived from the emissions from Hong Kong and Guangdong. Given that emissions from Guangdong and Hong Kong both contribute to pollution in Hong Kong, this implies that the inventory from the earlier PRD study and its speciation are generally consistent with the $\mathrm{C}_{6} \mathrm{H}_{14}$-to-toluene ratios observed at the sites during the field campaign.

\subsubsection{Ratios of alkanes}

An alternative approach involves using two sets of ratios of VOC species with differing lifetimes and assessing how these ratios should vary in the atmosphere as they dilute and react. Extrapolation of the so-called "dilution lines" and "reaction lines" back to time $=0$ allows one to use the observed ratios of the VOC to estimate the ratio of the emissions (see Mckeen and Liu (1993) for complete discussions of this technique). Here we use the ratios of n-butane-to-ethane and propane-to-ethane. Figure 9 gives the relationship between 
the two ratios at TO on all episode days with VOC data and that from the speciation of the two VOC inventories. The two lines represent how these ratios would evolve in time as result of dilution only and photochemistry only, assuming that the source is characterized of ratios close to the highest in the figure; note all the data points lie inside these two lines reflecting their evolution from both dilution and photochemistry. In fact, the source of the VOC should be on the right upper portion of the plot where the two lines intersect, since the major sources of VOC observed at TO are not local. However, the ratios obtained from inventories for both Hong Kong and Guangdong are located elsewhere. This suggests that the speciation of the VOC inventories in Hong Kong and Guangdong cannot be rationalized with the ratios observed during the measurement period.

\subsubsection{Summary}

Comparison of observed ambient ratios of selected VOC and their ratios in speciated VOC emission inventories for Hong Kong and PRD (or Guangdong Province) provide mixed results. For isomers of hexane and toluene reasonable consistency between the ambient data and the speciated inventory derived from the earlier PRD study was obtained. This is encouraging since toluene (along with the xylenes) was generally found to be among the most important VOC leading to the production of $\mathrm{O}_{3}$ pollution in Hong Kong. However, the ratios of low-molecular weight alkanes in the emission inventories for both Hong Kong and Guangdong Province could not be rationalized with ratios observed for these species in ambient air. Guo et al. (2006) also found discrepancies in source contributions from the TRACE-P emission inventory and by applying a principal component analysis to nonmethane volatile organic compounds at TO over the period of August 2001 to December 2002. One possible reason that causes the discrepancy could be the timing difference between the emission inventories and the observations, i.e. the source inventories are annual average data, while the measurements are only for October to December 2002 in this study. The lack of consistency could also reflect inaccuracies in the gross inventories or in the methodology used to speciate the inventory or in the measurements themselves. And, in this regard it should be noted that the speciation for both the TRACE-P inventory and the inventory from the earlier PRD study were based on emissions data obtained almost exclusively for sources operating in the United States and Europe and may very likely not be appropriate for sources operating in China, especially in PRD (as fuels in Hong Kong are imported and supplied by companies such as ExxonMobil and Shell, the source profile in Hong Kong area might probably be similar to that in the US and Europe). Clearly more measurements of the speciation of VOC sources in China will be needed in the future to resolve this issue.

It should be pointed out that the approach of using ratios of different VOC species has its limitations and uncertainties.
It uses surface/point measurements, thus the result lacks spatial representation and limited by measurement uncertainties. Comparison of the species ratios from ambient observation and emission inventory needs temporally constant composition of source emissions; all sources contributing to ambient concentrations at the receptor need to be identified; and the measurements should span a period of at least a whole year.

\section{Conclusions}

Measurements of VOC are analyzed to elucidate the sources impacting the Hong Kong area. The ratios, m,p-xylenes-toethylbenzene, $\mathrm{C}_{6} \mathrm{H}_{14}$-to-toluene, p-xylene-to-total xylenes, and $\mathrm{dSO}_{2} / \mathrm{dNO}_{\mathrm{y}}$ are used for diagnostic analyses. The photochemical age analysis based on $\mathrm{m}, \mathrm{p}$-xylenes-to-ethylbenzene shows that the source of the reactive aromatics, the most important species group in which xylenes and toluene are dominant, does not appear to be preferentially located in downtown Hong Kong, but in the downwind of downtown area and upwind of western Hong Kong. And the ratios of speciated VOC data, $\mathrm{C}_{6} \mathrm{H}_{14}$-to-toluene, p-xylene-to-total xylenes, imply that the source of the reactive aromatics does not appear to be dominated by mobile emissions except in the early morning hours of two episode days with anomalously high pollutant concentrations. Specifically emissions from industrial, waterfront, and fuel storage activities appear to be implicated.

VOC emission inventories by sector from Hong Kong and the PRD are speciated using emission profiles. The measurements are used to assess, in a preliminary way, the accuracy of emission inventories of VOC. The ratios of the concentrations of some VOC species (e.g., $\mathrm{C}_{6} \mathrm{H}_{14}$-to-toluene) are consistent with a speciated version of the VOC emission inventory produced from an earlier PRD study. The ratios of selected alkanes are not. The reason for this inconsistency could reflect inaccuracies in the inventory and/or the speciation method. VOC emissions in the region are dominated by reactive aromatics (e.g. xylenes and toluene). A significant contribution to the reactive aromatics present in the Hong Kong area appears to be coming from non-mobile sources.

Our results are based on observations at selected locations in Hong Kong during certain time period. The data on which our analyses are based are restricted spatially and temporally. More measurements would no doubt help characterize additional areas in more seasons and also check the accuracy of emission inventories more completely.

Acknowledgements. This work was supported by Hong Kong Jockey Club Charities Trust, Castle Peak Power Co. Ltd, the Environmental Protection Department of the Hong Kong Special Administrative Region, and Shell Hong Kong Ltd, through Civic Exchange. We thank Christine Loh and C. S. Kiang for coordinating the Pilot Study Project and Steven Poon for his valuable contribution to field measurement at Tai O. We also gratefully acknowledge Joey Kwok for his assistance in data processing. We 
are grateful to Chak Chan, Min Shao, and an anonymous reviewer who have provided many valuable suggestions for improving the manuscript. We appreciate Douglas Orsini for manuscript proofreading. Additional support to the PolyU team was provided by the Research Grants Council of the Hong Kong Special Administrative Region (Project No. PolyU 5144/04E). Partial financial support to BNU by NSFC (Project No. 40775076) and the Ministry of Science and Technology of China (Project No. 2005CB422207) is gratefully acknowledged.

Edited by: C. Chan

\section{References}

Barletta, B., Meinardi, S., Simpson, I. J., Zou, S. C., Rowland, F. S., and Blake, D. R.: Ambient mixing ratios of nonmethane hydrocarbons (NMHCs) in two major urban centers of the Pearl River Delta (PRD) region: Guangzhou and Dongguan, Atmos. Environ., 42, 4393-4408, 2008.

CH2M HILL (China) Limited: Final report: agreement No. CE 106/98: Study of Air Quality in the Pearl River Delta Region, April 2002.

Cass, G. R. and McRae, G. J.: Source-receptor reconciliation of routine air monitoring data for trace metals: An emission inventory assisted approach, Environ. Sci. Technol., 17, 129-139, 1983.

Chameides, W. L., Fehsenfeld, F., Rodgers, M. O., Cardelino, C., Martinez, J., Parrish, J. D., Lonneman, W., Lawson, D. R., Rasmussen, R. A., Zimmerman, P., Greenberg, J., Middleton, P., and Wang, T.: Ozone precursor relationships in the ambient atmosphere, J. Geophys. Res., 97, 6037-6055, 1992.

Chan, C. K. and Yao, X.: Air pollution in mega cities in China - a review, Atmos. Environ., 42, 1-42, 2008.

Chan, L. Y., Chu, K. W., Zou, S. S., Chan, C. Y., Wang, X. M., Barletta, B., Blake, D. R., Guo, H., and Tsai, W. Y.: Characteristics of nonmethane hydrocarbons (NMHCs) in industrial, industrialurban, and industrial-suburban atmospheres of the Pearl River Delta (PRD) region of south China, J. Geophys. Res., 111(D11), D11304, doi:10.1029/2005JD006481, 2006.

Chang, M. E., Hartley, D. E., Cardelino, C., and Chang, W.-L.: Inverse modeling of biogenic isoprene emissions, Geophys. Res. Lett., 23, 3007-3010, 1996.

Chang, M. E., Hartley, D. E., Cardelino, C., Haas-Lauresen, D., and Chang, W.-L.: On using inverse methods for resolving emissions with large spatial inhomogeneities, J. Geophy. Res., 102, 16023 16 036, 1997.

Colman, J. J., Swanson, A. L., Meinardi, S., Sive, B. C., Blake, D. R., and Rowland, F. S.: Description of the analysis of a wide range of volatile organic compounds in whole air samples collected during PEM-Tropics A and B, Anal. Chem., 73, 37233731, 2001.

Guo, H., Lee, S. C., Louie, P. K. K., and Ho, K. F.: Characterization of hydrocarbons, halocarbons and carbonyls in the atmosphere of Hong Kong, Chemosphere, 57, 1363-1372, 2004a.

Guo, H., Wang, T., and Louie, P. K. K.: Source apportionment of ambient non-methanehydrocarbons in Hong Kong: application of a principal component analysis (PCA)/absolute principal component scores (APCS) receptor model, Environ. Pollut., 129, 489-498, 2004b.
Guo, H., Wang, T., Blake, D. R., Simpson, I. J., Kwok, Y. H., and Li, Y. S.: Regional and local contributions to ambient non-methane volatile organic compounds at a polluted rural/coatal site in Pearl River Delta, China, Atmos. Environ., 40, 2345-2359, 2006.

Guo, H., So, K. L., Simpson, I. J., Barletta, B., Meinardi, S., and Blake, D. R.: $\mathrm{C}_{1}-\mathrm{C}_{8}$ volatile organic compounds in the atmosphere of Hong Kong: Overview of atmospheric processing and source apportionment, Atmos. Environ., 41, 1456-1472, 2007.

Hartley, D. and Prinn, R.: Feasibility of determining surface emissions of trace gases using an inverse method in a threedimensional chemical transport model, J. Geophys. Res., 98, 5183-5197, 1993.

Ho, K. F., Lee, S. C., and Chiu, G. M. Y.: Characterization of selected volatile organic compounds, polycyclic aromatic hydrocarbons and carbonyl compounds at a roadside monitoring station, Atmos. Environ., 36(1), 57-65, 2002.

Kok, G. L., Lind, J. A., and Fang, M.: An airborne study of air quality around the Hong Kong Territory, J. Geophys. Res., 102, 19043-19 057, 1997.

Lee, S. C., Chiu, M. Y., Ho, K. F., Zou, S. C., and Wang, X. M.: Volatile organic compounds (VOCs) in urban atmosphere of Hong Kong, Chemosphere, 48(3), 375-382, 2002.

Liu, Y., Shao, M., Lu, S., Chang, C. C., Wang, J. L., and Chen, G.: Volatile organic compound (VOC) measurements in the Pearl River Delta (PRD) region, China, Atmos. Chem. Phys., 8, 15311545, 2008, http://www.atmos-chem-phys.net/8/1531/2008/.

Mckeen, S. A. and Liu, S. C.: Hydrocarbon ratios and photochemical history of air masses, Geophys. Res. Lett., 20, 2363-2366, 1993.

Mulholland, M. and Seinfeld, J. H.: Inverse air pollution modeling of urban-scale CO emissions, Atmos. Environ., 28, 497-516, 1995.

Na, K., Kim, Y. P., Moon, I., and Moon, K.: Chemical composition of major VOC emission sources in the Seoul atmosphere, Chemosphere, 55, 585-594, 2004.

Nelson, P. F. and Quigley, S. M.: The m,p-xylenes:ethylbenzene ratio. A technique for estimating hydrocarbon age in ambient atmospheres, Atmos. Environ., 17, 659-662, 1983.

Parrish, D. D., Trainer, M., Buhr, M. P., Watkins, B. A., and Fehsenfeld, F. C.: Carbon monoxide concentrations and their relation to concentrations of total reactive oxidized nitrogen at two rural US sites, J. Geophys. Res., 96, 9309=-9320, 1991.

Schauer, J. J. and Cass, G. R.: Source apportionment of wintertime gas-phase and particle-phase air pollutants using organic compounds as tracers, Environ. Sci. Technol., 34, 1821-1832, 2000.

Schauer, J. J., Rogge, W. F., Hildemann, L. M., Mazurek, M. A., Cass, G. R., and Simoneit, B. R. T.: Source apportionment of airborne particulate matter using organic compounds as tracers, Atmos. Environ., 30, 3837-3855, 1996.

Sin, D. W. M., Wong, Y. C., and Louie, P. K. K.: Monitoring of ambient volatile organic compounds at two urban sites in Hong Kong from 1997 to 1998, Indoor Built Environ., 9, 216-227, 2000.

So, K. L. and Wang T.: $\mathrm{C}_{3}-\mathrm{C}_{12}$ non-methane hydrocarbons in subtropical Hong Kong: spatial-temporal variations, source-receptor relationships and photochemical reactivity, Sci. Total Environ., 328, 161-174, 2004. 
Streets, D. G., Bond, T. C., Carmichael, G. R., Fernandes, S. D., Fu, Q., He, D., Klimont, Z., Nelson, S. M., Tsai, N. Y., Wang, M. Q., Woo, J.-H., and Yarber, K. F.: An inventory of gaseous and primary aerosol emissions in Asia in the year 2000, J. Geophys. Res., 108(D21), 8809, doi:10.1029/2002JD003093, 2003.

Tan, Q., Chameides, W. L., Streets, D., Wang, T., Xu, J., Bergin, M., and Woo, J.: An evaluation of TRACE-P emission inventories from China using a regional model and chemical measurements, J. Geophys. Res., 109(D22), D22305, doi:10.1029/2004JD005071, 2004.

Tang, J. H., Chan, L. Y., Chan, C. Y., Li, Y. S., Chang, C. C., Liu, S. C., Wu, D., and Li, Y. D.: Characteristics and diurnal variations of NMHCs at urban, suburban, and rural sites in the Pearl River Delta and a remote site in South China, Atmos. Environ., 41, 8620-8632, 2007.

Tang, J. H., Chan, L. Y., Chan, C. Y., Li, Y. S., Chang, C. C., Wang, X. M., Zou, S. C., Barletta, B., Blake, D. R., and Wu, D.: Implications of changing urban and rural emissions on non-methane hydrocarbons in the Pearl River Delta region of China, Atmos. Environ., 42, 3780-3794, 2008.

USEPA: VOC/PM Speciation Database Management System (SPECIATE) - Version 3.2, United States Environmental Protection Agency, Research Triangle Park, North Carolina, USA, 2002.

Wang, T., Wu, Y. Y., Cheung, T. F., and Lam, K. S.: A study of surface ozone and the relation to complex wind flow in Hong Kong, Atmos. Environ., 35, 3203-3215, 2001.
Wang, T.: Study of visibility reduction and its causes in Hong Kong, Final report to the Environmental Protection Department, Hong Kong Special Administrative Region, 2003.

Wang, T., Guo, H., Blake, D. R., Kwok, Y. H., Simpson, I. J., and Li, Y. S.: Measurements of trace gases in the inflow of South China Sea background air and outflow of regional pollution at Tai O, Southern China, J. Atmos. Chem., 52(3), 295-317, 2005.

Wang, X., Sheng, G., Fu, J., Chan, C., Lee, S., Chan, L. Y., and Wang, Z.: Urban roadside aromatic hydrocarbons in three cities of the Pearl River Delta, People's Republic of China, Atmos. Environ., 36, 5141-5148, 2002.

Zhang, J., Chameides, W. L., Wang, T., and Kiang, C. S.: Ground-level ozone pollution in Hong Kong, final report, Civic Exchange, Hong Kong, http://www.civic-exchange.org/ eng/publication_ec.aspx, 2004.

Zhang, J., Wang, T., Chameides, W. L., Cardelino, C., Kwok, J., Blake, D. R., Ding, A., and So, K. L.: Ozone production and hydrocarbon reactivity in Hong Kong, Southern China, Atmos. Chem. Phys., 7, 557-573, 2007,

http://www.atmos-chem-phys.net/7/557/2007/.

Zheng, M., Cass, G. R., Schauer, J. J., and Edgerton, E. S.: Source apportionment of PM2.5 in the Southeastern United States using solvent-extractable organic compounds as tracers, Environ. Sci. Technol., 36, 2361-2371, 2002. 